\title{
ANALYSIS OF WOVEN NATURAL FIBER FABRICS PREPARED USING SELF-DESIGNED HANDLOOM
}

\author{
A.R. Azrin Hani ${ }^{1,2}$, M.F. Shaari ${ }^{2}$, N.S. Mohd Radzuan², M.S. Hashim², \\ R. Ahmad ${ }^{2}$ and M. Mariatti ${ }^{3}$ \\ ${ }^{1}$ Faculty of Engineering Technology, Universiti Tun Hussein Onn Malaysia, \\ Beg Berkunci 101, 86400 Parit Raja, Batu Pahat, Johor, Malaysia \\ Email: azrin@uthm.edu.my \\ ${ }^{2}$ School of Mechanical Engineering, University Sains Malaysia \\ Seri Ampangan, 14300 Nibong Tebal, Pulau Pinang, Malaysia \\ ${ }^{3}$ School of Materials and Mineral Resources Engineering, University Sains Malaysia \\ Seri Ampangan, 14300 Nibong Tebal, Pulau Pinang, Malaysia
}

\begin{abstract}
Interlacing of fiber bundles offers advantages in terms of good dimensional stability and high packing density. Woven fabric interlacing structure sourced from natural fiber (NF) has gained greater attention due to increasing environmental awareness. This study emphasizes the development of a weaving device suitable for yarns that are thick and coarse in structure. Furthermore, output analysis was performed on the fabrics and a static puncture test was conducted. Fabric analysis involved assessment of the fabric's characterization, such as fabric thickness, weight, density, wavelength and inter-yarn porosity. The fabric puncture test was conducted to determine the puncture resistance of the output produced. A tabletop weaving device was successfully developed in this research and is capable of weaving NF yarns with different degrees of fabric tightness. The results demonstrated that fabrics with lower porosity values have greater puncture resistance and a higher deflection rate of failure. It is apparent that the developed weaving device can produce tight woven structure fabrics from NF yarns with excellent puncture resistance.
\end{abstract}

Keywords: Woven; natural fiber; weaving device; fabric puncture.

\section{INTRODUCTION}

Woven is a continuous structure type of textile engineering reinforcement which leads to excellent characteristics such as higher intra- and interlaminar strength and damage resistance. Various researches have been conducted to identify its engineering performance and properties (Kim \& Sham, 2000; King, Jearanaisilawong, \& Socrate, 2005; Naik, Shrirao, \& Reddy, 2005, 2006; Tabiei \& Nilakantan, 2008; Cao et al., 2008; Rao et al., 2009; Nilakantan et al., 2010; Parsons et al., 2010). Commercial applications of woven textile include products for the automotive, aerospace, defense and biomedical industries, as explained by Mohanty, Misra, and Hinrichsen (2000), Cao et al. (2008) and Mcdaniels et al. (2009). Since the mid-1800s, research on natural fiber (NF) has evolved actively due to a greater consciousness of environmental issues including sustainability issues and insufficient petroleum reserves. However, when first produced, $\mathrm{NF}$ was used as discontinuous structure reinforcement. Until the 1900s, when the advantages offered by continuous woven structure were first realized, efforts had been made to explore its potential (Kamiya et al., 2000). The results indicated that continuous 
NF structure reinforcement improved the mechanical properties by a factor of three to four (Goutianos et al., 2006). Complementary works also showed that properties like the fracture toughness, ductility index and damage area were significantly improved (Kim \& Sham, 2000; Liu \& Hughes, 2008; Kushwaha \& Kumar, 2010). The available researches on woven NF fabrics were found to be very limited. Most of the reported research is focused on the woven structure from the fiber strand, which was prepared without any specific device. The existing weaving devices in the laboratory were found to be not ideally fit for the respective NF yarns used in this research. Figure 1 points up the problems that occur during the preparation of the woven. High friction rate rises during installation of the yarns on the floor loom led to very bad yarn hairiness. The condition became worse when the beating process was done, as the hairiness formed fiber hanks and restricted the movement of the reed. More force being exerted during beating causes the yarns to loosen in tension. Therefore, the weft yarns were unable to stay close to each other so as to form a denser fabric structure. As a result, the yarn interlacing was less tight and the structure was porous. This in turn increased the interyarn flow channel and the permeability of the fabric geometry, which led to a deterioration of its mechanical properties.
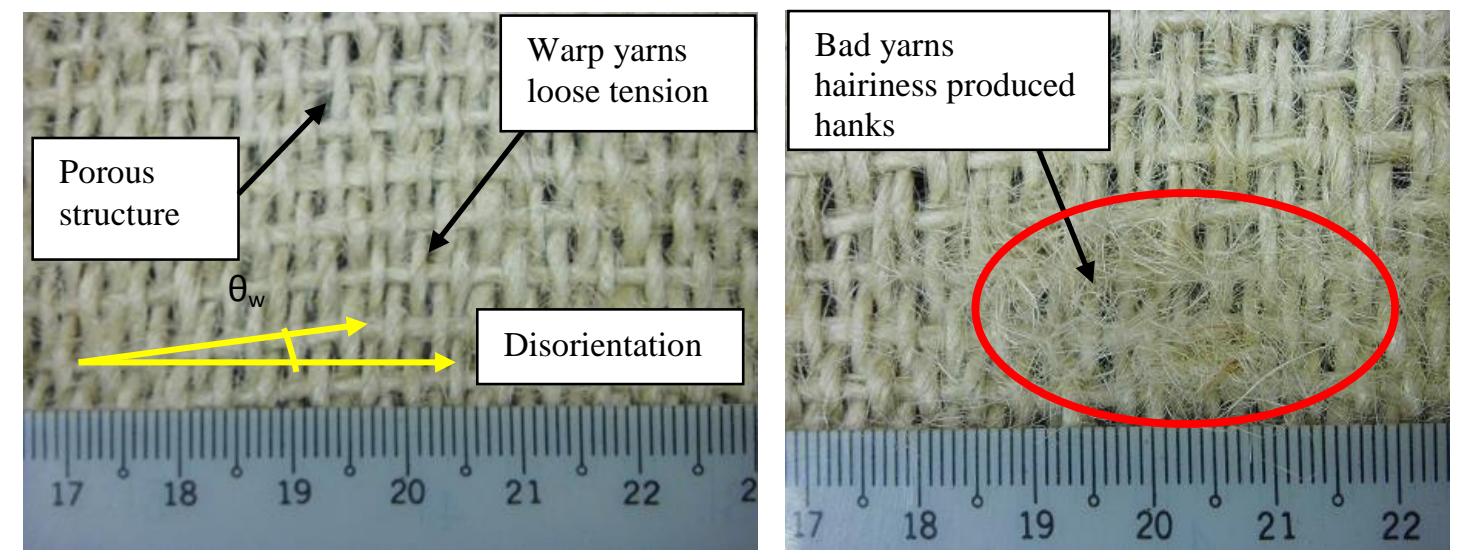

Figure 1. Failure of woven fabric.

The challenge addressed in the previous works triggered research in developing a weaving device suitable for yarns that are thick and coarse in structure. The output, which is the woven fabrics, was then analyzed. Two different fabric densities were produced from the device (Type 1 and Type 2) with the same yarn count (fineness). The properties and characterization of the as-received yarns and the fabrics produced were assessed and the puncture penetration resistance of the woven NF fabrics was studied. Assessment of the fabric characteristics involves analysis of the fabric thickness, weight, density, wavelength and inter-yarn porosity. The device designed for this research does not aim for fabric production efficiency. Nevertheless, the purpose of the design was to enable easy weaving of a complex structure of yarns from coarse NFs such as kenaf fiber and coconut coir fiber. 


\section{EXPERIMENTAL PROCEDURES AND MATERIALS}

\section{Development of Handloom}

Most of the woven NF geometry used in previous research was strictly dependent on the woven mat provided by the supplier. Modification to the weaving device (loom) is necessary to facilitate changes in the woven mat design. The need for device improvement is urgent and it presents device manufacturers with a challenge due to the demand for complex shapes of natural fibres. Besides, new complex woven designs have also become part of the challenge. The basic operational concept in interlacing yarns to produce fabrics on any type of loom is 'shedding', 'picking' and 'beating' (Collier et al., 2009). These three operations are often called the primary motions of weaving. Shedding involves opening up the vertical (warp) yarns direction in order to enable horizontal (weft) yarns to get in. The 'harness' was designed for this specific function. On the other hand, weft insertion of yarns or carrying yarns across the loom is called the 'picking' mechanism. Picking is usually assisted by a 'shuttle' device for a simple handloom. Beating is the final stage of the weaving process. Beating allows the incoming weft yarns to stay close to the other weft yarns to form the fabric. A 'reed' or 'comb' is designed for this purpose.

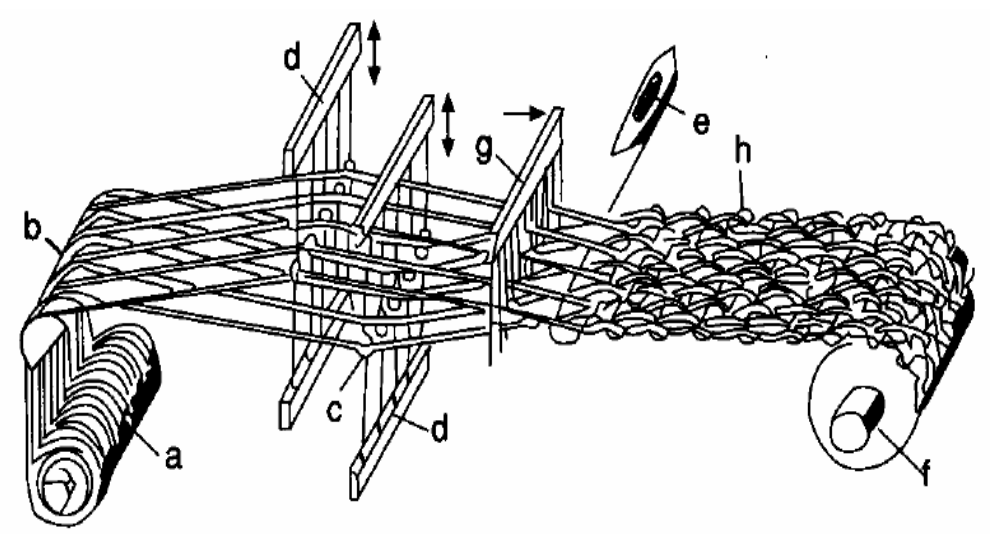

Figure 2. Essential parts of a loom: a-weaver's beam, b-back rest, c-healds (heddle), dheald frames, e-shuttle weft yarn, f-cloth beam, g-reed and h-woven cloth. (http://textilelibrary.wordpress.com/)

Generally there are numerous complex weaving loom mechanisms and machines that have been developed for mass production since the era of the industrial revolution. Figure 2 illustrates the schematic of a weaving device. Though numerous machines have been developed, the fundamentals of the weaving concept are still within the boundary of the three steps mentioned earlier. The shedding process is vital to defer the pattern of the produced fabric. This can be divided into two categories which are fixed shedding and programmable shedding. For fixed shedding, the heald frames move in opposite directions, bringing together all the yarn to the respective frame. This action creates a pathway for the shuttle to interlace the yarns. Unlike fixed shedding, programmable shedding has loose heddles that can only be moved depending on a written program.

The easiest picking or wefting process is done by moving the shuttle manually across the warping yarns. In advanced designs, the motion of the shuttle is driven by 
another mechanism such as a pneumatic or hydraulic driver. Seyam and El-Shiekh (1990) reported that a shuttleless loom is not efficient at weaving yarns having variations of thickness. Hence, this research employed a shuttle handloom for weft insertion due to the thickness discrepancies in natural fibers. Next, the beating process allows the formation of the fabric. The size of the reed or comb that is used to pull the yarns close together must consider the yarn fineness and fabric size. A bigger reed size results in fabrics with a porous structure. On the other hand, a smaller reed size can induce higher friction between the reed wire and yarns, ending in hairiness problems and loose tensioning of the warp yarns. Another issue that must be taken into consideration is the balanced pulling force of the reed. Any imbalanced force during the beating process could produce fabric with high porosity as well as fabric disorientation.

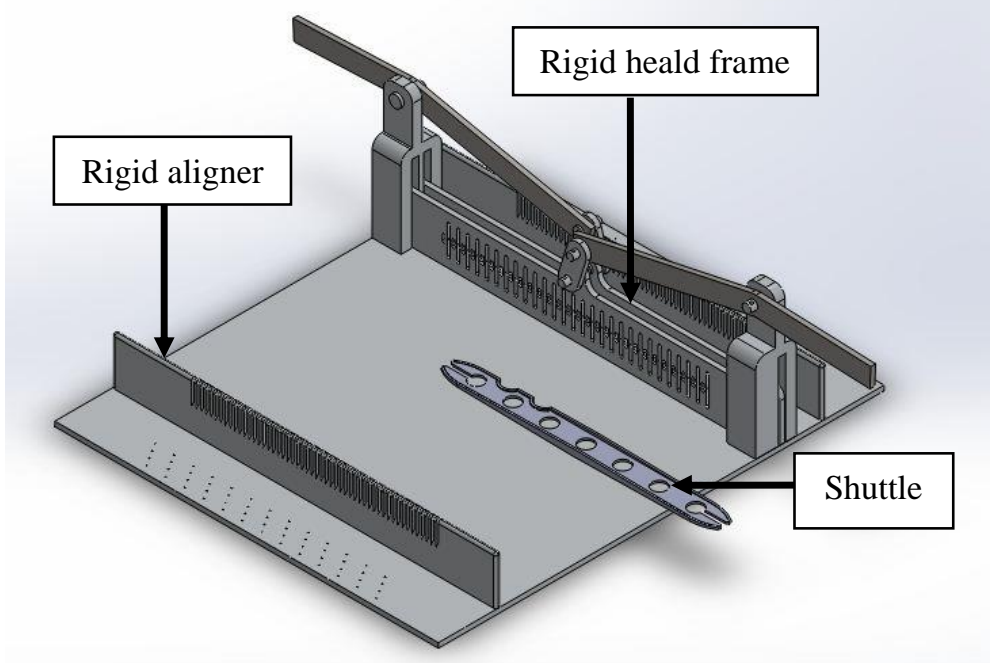

Figure 3. 3D model of the self-designed handloom.

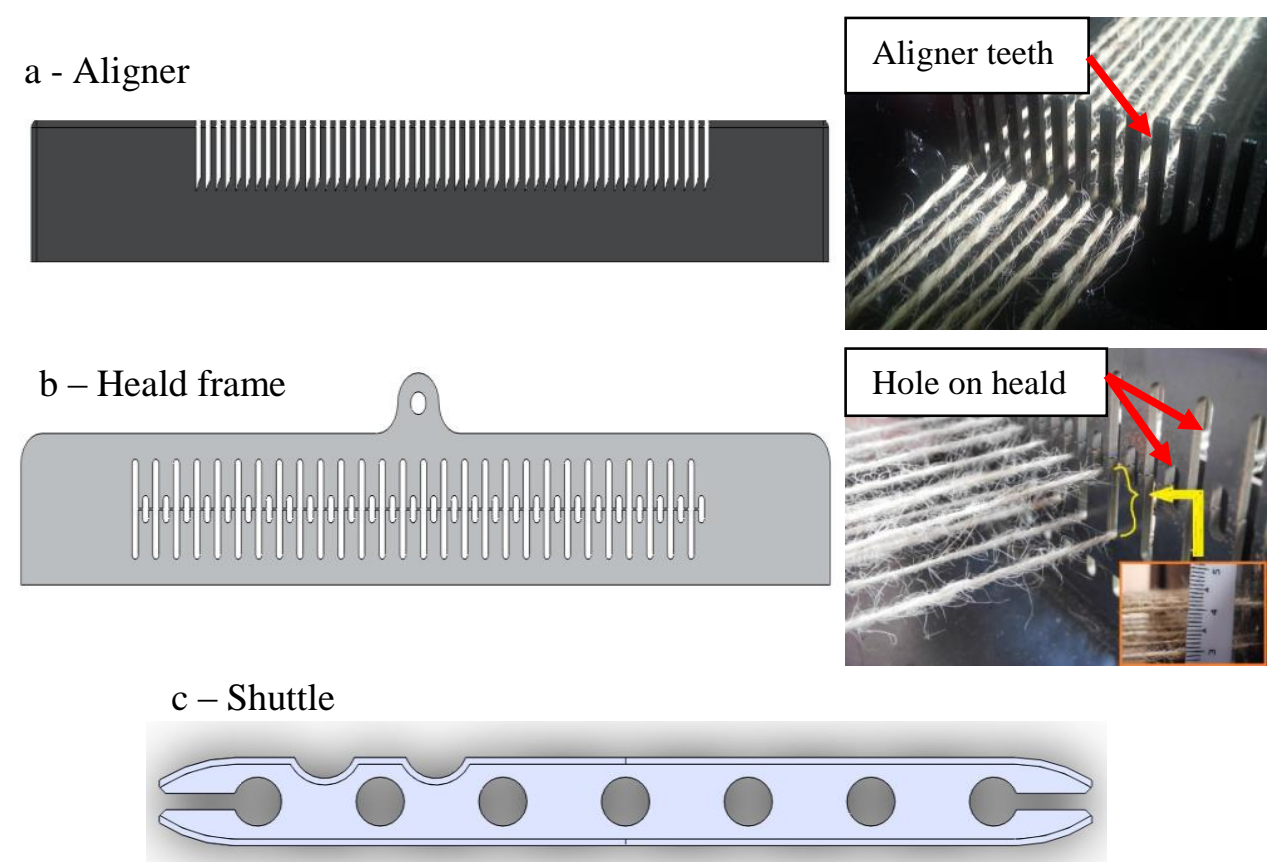

Figure 4. Representation of the main parts of the self-designed handloom. 
Figure 3 shows a 3D model of the self-designed handloom. The proposed design utilizes manual actuation for all three basic weaving operations. This prototype manages to produce fabric with dimensions of $230 \mathrm{~mm}$ x $230 \mathrm{~mm}$. The overall size of the weaver is $465 \mathrm{~mm} \times 400 \mathrm{~mm} \times 145 \mathrm{~mm}(\mathrm{~L} \mathrm{x} \mathrm{W} \mathrm{x} \mathrm{H})$. It consists of five major components: the base with pin holder, the front reed aligner, the rear reed aligner and the two heald frames. Figure 4 illustrates the main parts of the handloom. The base was made from mild steel to retain the components' positions during weaving. The pin holders were attached at both ends of the base to tie the yarn in the Y-axis position. In order to ensure the aligned yarn is in the right position, an aligner was fixed near the finishing end pin holder. As this prototype was designed for a laboratory woven sample, no rolling mechanism was attached at the end pin holder. Heald frames were located $265 \mathrm{~mm}$ from the front aligner so that the produced sample would have a length of around $230 \mathrm{~mm}$ in the Y-axis. Both frames were actuated using a lever-pivot mechanism. The maximum lift elevation recorded between the two frames was a $10 \mathrm{~mm}$ gap.

\section{Materials and Woven Fabrication}

Coir and kenaf natural yarns were supplied from BTex Engineering Ltd., India and Juteko Co. Ltd., Bangladesh respectively. The photograph of the NF yarn structure is shown in Figure 5. It was seen that the as-received yarns exhibited a relatively high rate of hairiness, and were thick and coarse in structure. As mentioned earlier, fabrics were produced in two different types: Type 1 and Type 2. Selection of the woven type was based on the highest degree of woven tightness that the device can produce. The extensive report from a previous work had shown that fabric tightness is highly correlated to fabric properties. It also revealed that fabric tightness significantly affects weaving resistance (Seyam \& El-Shiekh, 1994). Fabric Type 1 had a warp distance of $10 \mathrm{~mm}$, produced using an aligner size of $10 \mathrm{~cm}$ gaps between each tooth and a heald size of $10 \mathrm{~mm}$ gaps between each hole. On the other hand, fabric Type 2 (a warp distance of $5 \mathrm{~mm}$ ) was produced using a $5 \mathrm{~mm}$ gap size between teeth on the aligner and $5 \mathrm{~mm}$ gaps between the holes on the heald frame.

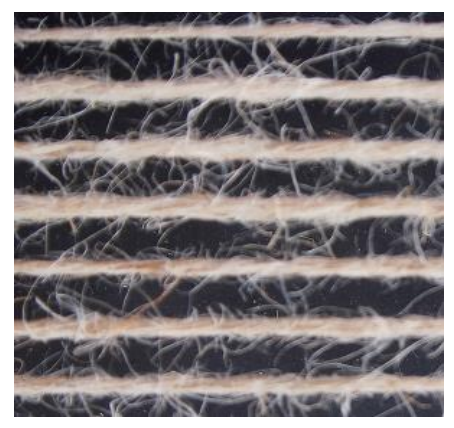

(a)

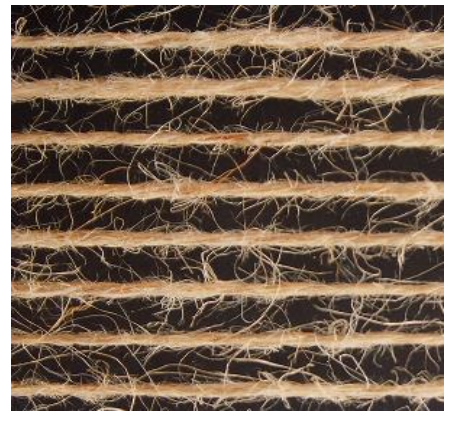

(b)

Figure 5. Yarns: (a) kenaf and (b) coir.

\section{Testing and Characterization of As-Received Yarns}

Characterization of as received yarns was carried out in this research. Yarn fineness (in Tex) was conducted according to ASTM D 2260. This was determined by weighing specified lengths of yarns and converting the data to the appropriate unit. On the other 
hand, the yarn types and yarn twist directions were also been observed. Coir and kenaf yarns were randomly selected for a tension test using a Universal Testing Machine Lloyd $30 \mathrm{~K}$. A load cell of $500 \mathrm{~N}$ was used. A uniform pre-tension of $2 \mathrm{~N}$ was applied and the gauge length was $100 \mathrm{~mm}$. The selected crosshead speed was $2 \mathrm{~mm} / \mathrm{min}$. The specified gauge length was chosen with reference to the study by Subaida et al. (2008), in which they found that most of the strongest fibers are of lengths between 100 and 150 mm. Breaking strength (MPa), breaking strain (\%) and Young's modulus data was recorded.

\section{Testing and Characterization of Fabric Produced}

Figure 6 illustrates a model of plain weave fabric. $\mathrm{P}_{1}$ and $\mathrm{P}_{2}$ represent the distance between warp yarns and weft yarns. Meanwhile, $d_{1}$ and $d_{2}$ denote the warp and weft yarn circular diameter. $t$ refers to the fabric thickness while $\lambda$ indicates the fabric wavelength. The wavelength of the weft is defined by the distance over which the warp pitch wave repeats. The fabric characterization analysis involved fabric thickness testing, fabric weight, fabric density, fabric wavelength and inter-yarn fabric porosity. Fabric thickness (t) was measured using a digital caliper. Fabric weight, on the other hand, was determined by weighing fabric specimens of a predetermined size on a scale. Fabric weight in grams/meter ${ }^{2}$ was calculated from the weight of the area measured. The density of a fabric is weighed relative to thickness, expressed in grams/centimeter ${ }^{3}$. In contrast, the warp and weft density were reported separately and expressed in warp/weft per inch. The weft wavelength was also measured in order to see the crimp effects of the structure. Finally, inter-yarn fabric porosity, $\varepsilon$ was calculated using Eq. (1). Porosity is defined as the ratio of the projected geometrical area of the opening across the material to the total area of the material (Çay, Atav, \& Duran, 2007).

$$
\varepsilon=\frac{\text { open pore area }}{\text { total area }}=\frac{P_{1}-P_{2}}{\left(P_{1}+d_{1}\right)\left(P_{2}+d_{2}\right)}
$$

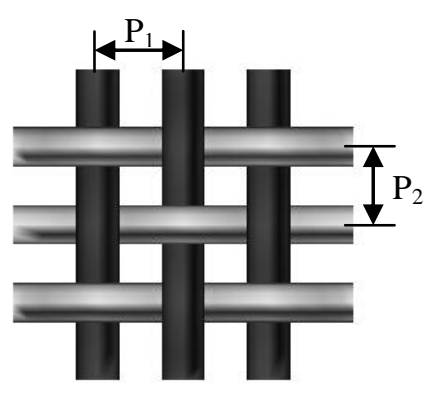

(a)

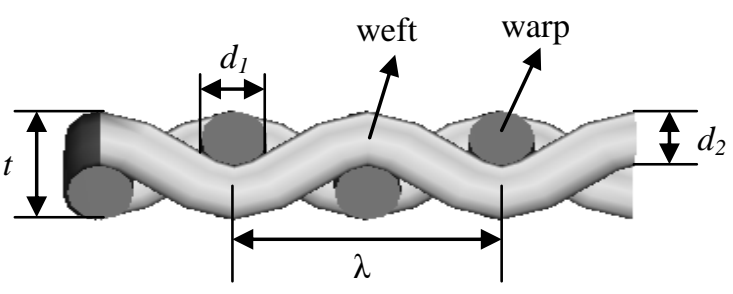

(b)

Figure 6. Model of plain weave fabric: (a) top view and (b) cross-section view.

The fabric puncture test was performed on an Instron Tensile Machine (Model 5582) according to the procedures and dimensions described by Briscoe and Motamedi as mentioned in Hassim et al. (2011). This was a modified puncture resistance test according to ASTM F1342. The test was conducted to measure the force required to penetrate or puncture the dry woven fabric and the amount of deflection that the fabric gains upon penetration. Details of the methods are well explained in Hassim et al. 
(2011). A $5 \mathrm{kN}$ load cell was used at a constant speed of $50 \mathrm{~mm} / \mathrm{min}$. The probe used was conical in shape and made of stainless steel with a diameter of $25.4 \mathrm{~mm}$. It was positioned with its tip just touching the fabric's surface as shown in Figure 7.

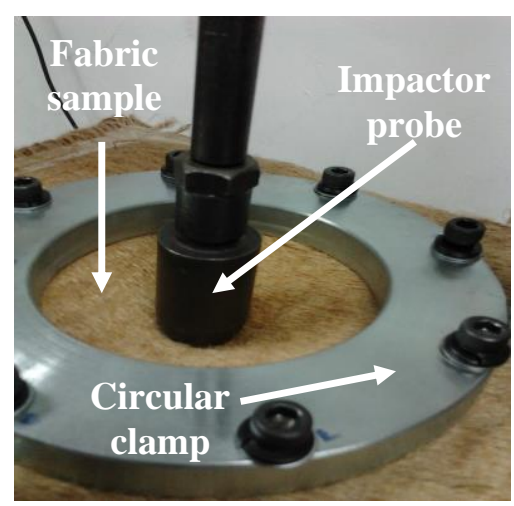

Figure 7. Puncture test on fabric.

\section{RESULTS AND DISCUSSION}

\section{Characterization and Properties of As-Received Yarns}

The characterization and properties of the as-received yarns are given in Table 1. The overall differences in properties between the two yarns were found to be not too significant. Coir was found to exhibit a slightly higher Young's modulus than kenaf yarns. Coir yarns were also found to be a little bit finer than kenaf yarns.

Table 1. Properties of as-received yarns.

\begin{tabular}{lcc}
\hline Properties & Kenaf & Coir \\
\hline Yarn fineness (Tex) & 946 & 923 \\
Yarn type & 1 ply spun & 2 ply spun \\
Twist direction & Z-twist & S-twist \\
Average breaking strength (MPa) & 139 & 129 \\
Average breaking strain $(\%)$ & 4.2 & 3.0 \\
Young's modulus $(\mathrm{GPa})$ & 5.6 & 6.6 \\
\hline
\end{tabular}

\section{Characterization and Properties of Produced Fabric}

Table 2 illustrates the physical characterization of the woven fabric produced using the self-designed handloom. T1 refers to woven Type 1 and T2 refers to woven Type 2 . The results show that the Type 1 fabric exhibited greater thickness and weight. This was due to the greater number of yarns in the weft direction but a slightly lower amount of warp per inch. As reported by Kotb (2012), the density of the warp ends has negative effects on fabric thickness and this research confirmed that finding. However, the effects of the weft density on fabric thickness found in this research displayed a contradictory result due to the irregular warp density employed. Fabric Type 1 also presents higher interyarn fabric porosity than Type 2 fabrics. On the other hand, Type 2 structures presented higher crimp effects as a result of lower wavelength. Typical curves of puncture load $(\mathrm{N})$ versus extension $(\mathrm{mm})$ for the puncture resistance test of all the woven fabric 
samples are shown in Figure 8. It can be seen that fabrics with lower inter-yarn fabric porosity demonstrate higher penetration resistance. In this case, coir Type 2 exhibited the highest impact load followed by kenaf Type 2 . The reason was most likely because higher forces are required to penetrate fabrics with a tight structure. This result is in accordance with the study by Fatahi and Yazdi (2010), which explained that the fabric strength decreased with an increment of fabric inter-yarn channel (pore value). In comparing kenaf and coir fabric, coir was found to resist a higher penetration load. Previous research, particularly on kenaf and coir composite, also proved that coir demonstrated better impact strength resistance than kenaf (Azrin Hani et al., 2013). Extension at maximum load for Type 2 fabrics showed a considerable increment compared with Type 1 fabrics. Coir Type 2 presented the highest extension value at peak load. Research done by Abou Nassif (2012) reported that when the fabric weft density reached 71 weft/inch, the fabric breaking elongation decreased. This research revealed that the higher weft density contributed to lower elongation at maximum load. From the result, coir displayed better elongation at failure compared to kenaf and this is in accordance with the previous work done by Akil et al. (2011).

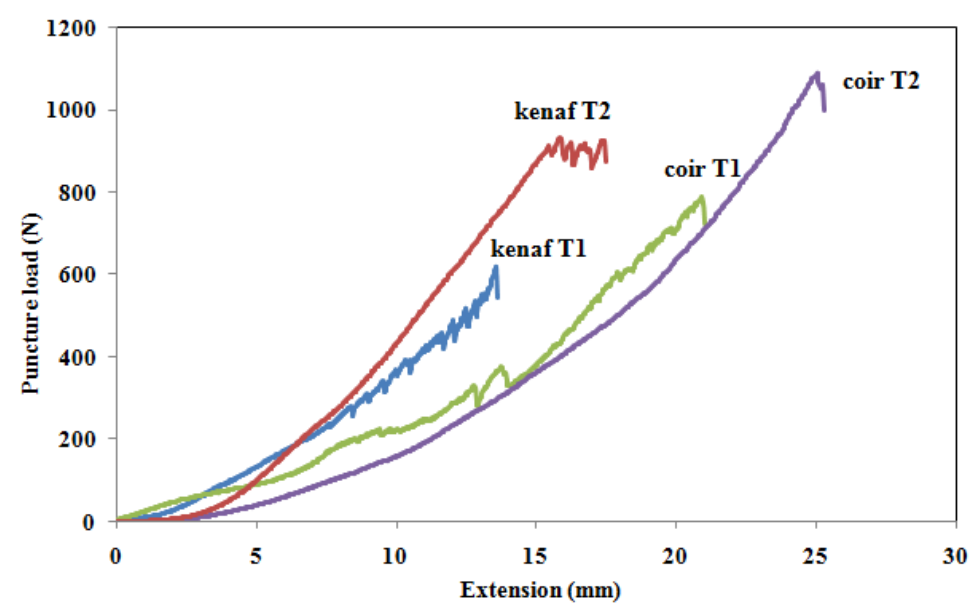

Figure 8. Puncture load versus extension of woven Type 1 and Type 2.

Table 2. Characterization of woven fabric produced.

\begin{tabular}{lcccc}
\hline \multirow{2}{*}{ Characterization } & \multicolumn{2}{c}{ Kenaf } & \multicolumn{2}{c}{ Coir } \\
\cline { 2 - 5 } & Type 1 & Type 2 & Type 1 & Type 2 \\
\hline Thickness, t $(\mathrm{mm})$ & 2.7 & 2.1 & 2.4 & 2.2 \\
Weight $\left(\mathrm{g} / \mathrm{m}^{2}\right)$ & 5800 & 4400 & 5600 & 4600 \\
Density $\left(\mathrm{g} / \mathrm{cm}^{3}\right)$ & 2.1 & 2.1 & 2.3 & 2.1 \\
Warp density (warp/inch) & 3 & 5 & 3 & 5 \\
Weft density (weft/inch) & 31 & 21 & 31 & 21 \\
Wavelength, $\lambda$ (mm) & 20 & 10 & 20 & 10 \\
Inter-yarn fabric porosity $(\varepsilon)$ & 0.346 & 0.198 & 0.346 & 0.198 \\
\hline
\end{tabular}

\section{CONCLUSION}

A weaving device for the NF coarse yarn structure was successfully developed in this research, eliminating the disorientation of yarns and producing a woven structure that 
was less porous. Fabrication of close tightly woven structure was achieved using the designed handloom with a fabric thickness of as low as $2.1 \mathrm{~mm}$ and a density of 2.1 $\mathrm{g} / \mathrm{cm}^{3}$ for approximately 1.0 to $1.3 \mathrm{~mm}$ yarn diameter. The woven tightness can be varied by adjusting the healds frame and aligner. The device output (woven Type 2) was found to achieve lower fabric inter-yarn porosity with a lower wavelength. Type 2 woven structures also demonstrated the highest puncture resistance with superior extension at maximum load.

\section{ACKNOWLEDGMENTS}

Special appreciation goes to the Faculty of Applied Sciences, Universiti Teknologi MARA (UiTM), Malaysia for permission and assistance using the facilities. The authors would also like to thank Universiti Sains Malaysia (USM), for awarding the research grant (USM-RU-PGRS; grant no. 8045019) that made this study possible. Besides, this research is also being supported by the Advanced Textile Training Centre (ADTEC), Universiti Tun Hussein Onn Malaysia (UTHM).

\section{REFERENCES}

Abou Nassif, G. A. (2012). Effect of weave structure and weft density on the physical and mechanical properties of micro polyester woven fabrics. Life Science Journal, 9(3), 2-7.

Akil, H. M., Omar, M. F., Mazuki, A. A. M., Safiee, S., Ishak, Z. A. M., \& Abu Bakar, A. (2011). Kenaf fiber reinforced composites: A review. Materials and Design, 32(8-9), 4107-4121.

Azrin Hani, A. R., Chan, T. S., Ahmad, R., \& Mariatti, M. (2013). Impact and flexural properties of imbalance plain woven coir and kenaf composite. Applied Mechanics and Materials, 271-272, 81-85.

Cao, J., Akkerman, R., Boisse, P., Chen, J., Cheng, H. S., De Graaf, E. F., Gorczyca, J. L., et al. (2008). Characterization of mechanical behavior of woven fabrics: Experimental methods and benchmark results. Composites Part A: Applied Science and Manufacturing, 39(6), 1037-1053.

Çay, A., Atav, R., \& Duran, K. (2007). Effects of warp-weft density variation and fabric porosity of the cotton fabrics on their colour in reactive dyeing. Fibres \& Textiles in Eastern Europe, 15(1), 91-94.

Collier, B. J., Bide, M., \& Tortora, P. G. (2009). Understanding textiles. Upper Saddle River, NJ: Pearson.

Fatahi, I. \& Alamdar Yazdi, A. (2010). Assessment of the relationship between air permeability of woven fabrics and its mechanical properties. Fibres and Textiles in Eastern Europe, 18(6), 68-71.

Goutianos, S., Peijs, T., Nystrom, B., \& Skrifvars, M. (2006). Development of flax fibre based textile reinforcements for composite applications. Applied Composite Materials, 13(4), 199-215.

Hassim, N., Ahmad, M. R., Wan Ahmad, W. Y., Samsuri, A., \& M Yahya, M. H. (2011). Puncture resistance of natural rubber latex unidirectional coated fabrics. Journal of Industrial Textiles, 4(2), 1-14.

Kamiya, R., Cheeseman, B. A, Popper, P., \& Chou, T.-W. (2000). Some recent advances in the fabrication and design of three-dimensional textile preforms: a review. Composites Science and Technology, 60(1), 33-47. 
Kim, J.-K. \& Sham, M.-L. (2000). Impact and delamination failure of woven-fabric composites. Composites Science and Technology, 60(5), 745-761.

King, M. J., Jearanaisilawong, P., \& Socrate, S. (2005). A continuum constitutive model for the mechanical behavior of woven fabrics. International Journal of Solids and Structures, 42(13), 3867-3896.

Kotb, N. A. (2012). The perception of plain woven fabrics' performance using regression analysis. Journal of Basic and Applied Scientific Research, 2(1), 2026.

Kushwaha, P. K. \& Kumar, R. (2010). The studies on performance of epoxy and polyester-based composites reinforced with bamboo and glass fibers. Journal of Reinforced Plastics and Composites, 29(13), 1952-1962.

Liu, Q. \& Hughes, M. (2008). The fracture behaviour and toughness of woven flax fibre reinforced epoxy composites. Composites: Part A, 39, 1644-1652. doi:10.1016/j.compositesa.2008.07.008.

Mcdaniels, K., Downs, R. J., Meldner, H., Beach, C., \& Adams, C. (2009). High strength-to-weight ratio non-woven technical fabrics for aerospace applications. Cubic Tech Corp.

Mohanty, A. K., Misra, M., \& Hinrichsen, G. (2000). Biofibres, biodegradable polymers and biocomposites: An overview. Macromolecular Materials and Engineering, 276-277(1), 1-24. doi:10.1002/(SICI)1439-2054(20000301)276:1<1::AIDMAME1>3.0.CO;2-W.

Naik, N. K., Shrirao, P., \& Reddy, B. C. K. (2005). Ballistic impact behaviour of woven fabric composites: Parametric studies. Materials Science and Engineering: A, 412(1-2), 104-116.

Naik, N. K, Shrirao, P., \& Reddy, B. C. K. (2006). Ballistic impact behaviour of woven fabric composites: Formulation. International Journal of Impact Engineering, 32(9), 1521-1552.

Nilakantan, G., Keefe, M., Bogetti, T. A., Adkinson, R., \& Gillespie Jr., J. W. (2010). On the finite element analysis of woven fabric impact using multiscale modeling techniques. International Journal of Solids and Structures, 47(17), 2300-2315.

Parsons, E. M., Weerasooriya, T., Sarva, S., \& Socrate, S. (2010). Impact of woven fabric: Experiments and mesostructure-based continuum-level simulations. Journal of the Mechanics and Physics of Solids, 58(11), 1995-2021.

Rao, M. P., Nilakantan, G., Keefe, M., Powers, B. M., \& Bogetti, T. A. (2009). Global/local modeling of ballistic impact onto woven fabrics. Journal of Composite Materials, 43(5), 445-467.

Seyam, A. \& El-Shiekh, A. (1990). Mechanics of woven fabrics: Part I: Theoretical investigation of weavability limit of yarns with thickness variation. Textile Research Journal, 60(7), 389-404.

Seyam, A. \& El-Shiekh, A. (1994). Mechanics of woven fabrics: Part IV: Critical review of fabric degree of tightness and its applications. Textile Research Journal, 64(11), 653-662.

Subaida, E. A., Chandrakaran, S., \& Sankar, N. (2008). Experimental investigations on tensile and pullout behaviour of woven coir geotextiles. Geotextiles and Geomembranes, 26(5), 384-392.

Tabiei, A. \& Nilakantan, G. (2008). Ballistic impact of dry woven fabric composites: A review. Applied Mechanics Reviews, 61(1), 010801.

Textile Library. http://textilelibrary.wordpress.com/, accessed on 14-01-2013. 